\title{
Focus on noninvasive respiratory support before and after mechanical ventilation in patients with acute respiratory failure
}

\author{
Audrey De Jong ${ }^{1,2}$, Jonathan D. Casey ${ }^{3}$ and Sheila Nainan Myatra ${ }^{4^{*}}$ (1)
}

๑) 2020 Springer-Verlag GmbH Germany, part of Springer Nature

The recent literature provides new insights into the potential of noninvasive respiratory support to prevent tracheal intubation (TI), improve the safety of TI, and support patients following extubation. In this article, we discuss how such data can be used to improve patient care (Fig. 1).

\section{Oxygen therapy in patients with acute respiratory failure}

High flow nasal oxygen (HFNO) devices are capable of providing up to $100 \%$ oxygen at flow rates up to $70 \mathrm{~L}$ per minute (exceeding inspiratory flow rates). In addition to noninvasively providing a high fraction of inspired oxygen, HFNO has been shown to have physiologic benefits including provision of a low level of continuous positive airway pressure, decreased work of breathing and dead space washout $[1,2]$. Prior studies have suggested that HFNO may be superior to conventional oxygen therapy (COT) and noninvasive ventilation (NIV) in treating acute hypoxemic respiratory failure [3] while other trials have shown no difference in outcomes [4]. This question was further explored in a recent systematic review and meta-analysis [5]. Across nine RCTs and 2,093 patients, Rochwerg et al. demonstrated that HFNO, compared to COT, reduced the need for TI and escalation of respiratory support but did not appear to affect mortality. However, the meta-analysis included a very heterogeneous population, some studies were at a high risk of bias and

\footnotetext{
*Correspondence: sheila150@hotmail.com

${ }^{4}$ Department of Anaesthesiology, Critical Care and Pain, Tata Memorial Hospital, Homi Bhabha National Institute, Dr. Ernest Borges Road, Parel, Mumbai, India

Full author information is available at the end of the article
}

accurate subgroup analyses could not be performed, suggesting a need for further research.

\section{Optimizing oxygenation and ventilation during tracheal intubation}

Hypoxemia is the most common complication during TI of critically ill patients [6].Oxygenation and ventilation can be provided at three distinct phases of the TI: preoxygenation, induction to laryngoscopy, and laryngoscopy to TI. Studies conducted in 2019 evaluated the use of HFNO and NIV in all the three phases of TI [7]. Following up on the PREOXYFLOW study from 2015 [8], which evaluated HFNO during the TI of patients with acute hypoxemic respiratory failure, Guitton et al. conducted the PROTRACH study [9] among patients without pre-existing hypoxemia undergoing TI in the ICU $(\mathrm{PaO} 2 / \mathrm{FiO} 2$ ratio $\geq 200 \mathrm{mmHg})$.The study randomized 192 patients to HFNO (which was continued throughout the procedure) or to oxygen by face mask (which was removed for laryngoscopy). HFNO failed to increase the lowest oxygen saturation during intubation (the primary outcome), but several secondary outcomes including mild hypoxemia (oxygen saturation $<90 \%$ ) favored HFNO. While the results favored HFNO over COT during $\mathrm{TI}$, the trial failed to meet its primary outcome and must be interpreted in the context of the PREOXYFLOW trial which failed to show benefit among hypoxemic patients who would have been expected to have a larger benefit [10-12].

The failure of HFNO to provide more robust improvements in oxygen saturation during TI may be explained by a recent physiologic study [13], which demonstrated a significantly higher end-tidal oxygen following pre-oxygenation with face mask, compared to HFNO, suggesting

\section{Springer}


Noninvasive Respiratory Support before and after Mechanical Ventilation in Patients with Acute Respiratory Failure
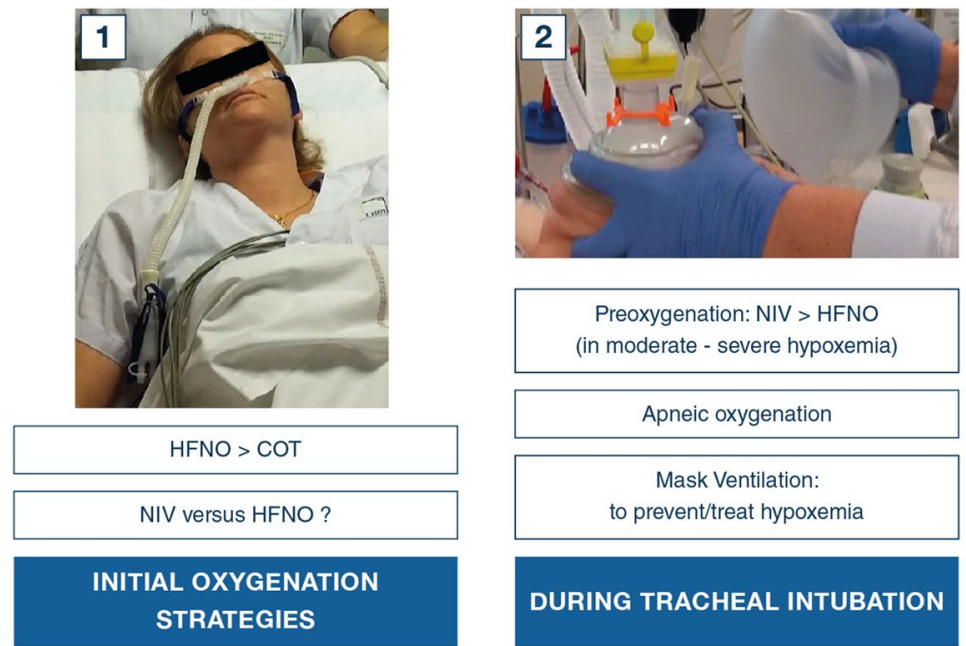

Preoxygenation: NIV > HFNO (in moderate - severe hypoxemia)

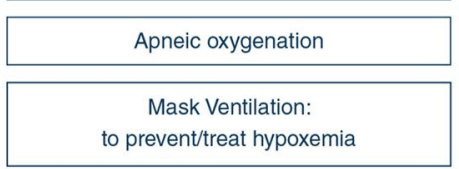

DURING TRACHEAL INTUBATION

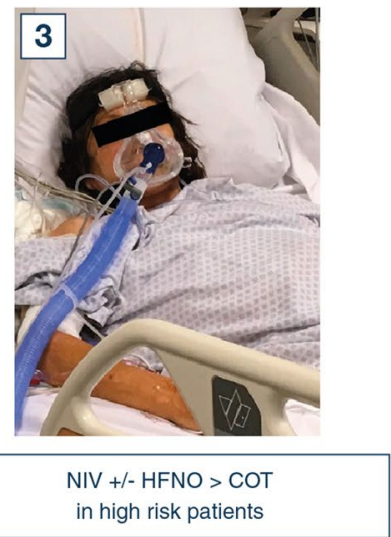

AFTER EXTUBATION

Fig. 1 Noninvasive respiratory support before and after mechanical ventilation in patients with acute respiratory failure. (1) Initial oxygenation strategies: Further studies are still needed to compare the three main methods of oxygenation: COT, HFNO and NIV(with different interfaces and in different settings) to avoid intubation in patients with acute respiratory failure. (2) During tracheal intubation: Preoxygenation using NIV remains the more efficient strategy to decrease oxygen desaturation in critically ill patients. Gentle mask ventilation during apnea before tracheal intubation, may help to further reduce the incidence of severe hypoxemia. (3) After extubation: Early extubation followed by NIV application with or without HFNO, may reduce the rate of respiratory failure and re-intubation. Further studies are needed in selected subgroups of patients. HFNO: high-flow nasal cannula oxygen; NIV = noninvasive ventilation; COT= conventional oxygen therapy

that the intake of room air by mouth during HFNO may outweigh its other physiologic benefits during TI. OPTINIV, a proof of concept study [14], showed that during TI adding HFNO for apneic oxygenation to NIV for preoxygenation was more effective in reducing the severity of desaturation compared to NIV alone.

In a study closely related to the PROTRACH study [9], Frat et al. [15] conducted the FLORALI2, which randomized 322 hypoxemic, critically adults undergoing TI to NIV(from induction to laryngoscopy) or HFNO (from induction to $\mathrm{TI})$. The incidence of severe hypoxemia during TI was $23.2 \%$ in the NIV group and $27.5 \%$ in the HFNO group (absolute difference $-4.2 \%$; 95\% CI - 13.7\% to $5.5 \% ; P=0.39$ ). However, subgroup analyses suggested a potential benefit for NIV among patients with a $\mathrm{P} / \mathrm{F}$ ratio $<200$. Taken together with prior trials, the results of the FLORALI 2 trial suggest that NIV may be the best method of preoxygenation to reduce oxygen desaturation during TI of critically ill patients, particularly among patients at high risk [16].

While the PROTRACH [9] and FLORALI 2 [16] trials focused on preoxygenation, management of the period from induction to laryngoscopy has been similarly controversial. Following induction there is a period where the patient may be apneic or hypopneic. Bag-mask ventilation during this period may prevent hypoxemia but has been proposed to increase the risk of gastric insufflation and pulmonary aspiration. In the PREVENT study, Casey et al. [17] randomized 401 patients to receive bagmask ventilation from induction to laryngoscopy or no ventilation, except as treatment of hypoxemia. Bag-mask ventilation reduced the incidence of severe hypoxemia (oxygen saturation $<80 \%$ ) by more than half, without increasing the rate of pulmonary aspiration. The trial, however, was not powered to provide a definitive assessment of the relationship between bag-mask ventilation and pulmonary aspiration.

Applying positive pressure seems beneficial not only during apneic periods but also during pre-oxygenation, raising the question of the potential role of NIV applied from pre-oxygenation to laryngoscopy.

\section{Oxygenation and ventilation following extubation}

Protocols for daily spontaneous awakening and breathing trials have shortened the average duration of mechanical ventilation and improved outcomes. However, there are still patients who recurrently fail spontaneous breathing trials and require a prolonged wean from ventilation. Vaschetto et al. [18] evaluated the effect of extubation without performing a spontaneous breathing trial followed by NIV application Among 130 non-hypercapnic patients ventilated more than $48 \mathrm{~h}$ (after exclusion of 
patients with acute respiratory failure secondary to neurologic disorders, status asthmaticus, COPD, and cardiogenic pulmonary edema and obese patients), it appeared that early extubation reduced the duration of invasive mechanical ventilation but did not affect ICU length of stay.

Other studies have explored the role for HFNO and NIV following extubation to prevent recurrent respiratory failure or hypotension [19]. Thille et al. [20] compared post-extubation support with NIV and HFNO to post-extubation with HFNO alone. Among 648 patients at high risk of reintubation (older than 65 years or with an underlying cardiac or respiratory disease), the investigators found that NIV with HFNO reduced reintubation rates. This study adds to a growing consensus that high-risk patients benefit from post-extubation support. However, each study of post-extubation support has used different criteria to define risk status, and further research is needed to validate these risk factors and determine if there are other populations who would benefit from post-extubation support.

\section{Conclusion}

Studies in the past year have improved our knowledge about the conditions for which noninvasive respiratory support devices may provide benefit. While further research is needed, it appears that preoxygenation with NIV and gentle bag-mask ventilation after induction reduce the risk of peri-procedural hypoxemia, while the combination of HFNO and NIV may prevent desaturation during TI and respiratory failure and reintubation following extubation.

\footnotetext{
Author details

1 INSERM U1046, CNRS UMR 9214, University of Montpellier, Montpellier Cedex 5, France. ${ }^{2}$ Anesthesia and Critical Care Department B, Saint Eloi Teaching Hospital, Centre Hospitalier Universitaire Montpellier, 34295 Montpellier Cedex 5, France. ${ }^{3}$ Department of Allergy, Pulmonary, and Critical Care, Vanderbilt University Medical Center, Nashville, TN, USA. ${ }^{4}$ Department of Anaesthesiology, Critical Care and Pain, Tata Memorial Hospital, Homi Bhabha National
} Institute, Dr. Ernest Borges Road, Parel, Mumbai, India.

\section{Funding}

JDC was supported by the NIH/NHLBI (K12HL133117).

\section{Compliance with ethical standards}

\section{Conflicts of interest}

ADJ, JDC and SNM have no conflict of interest.

Ethics approval and consent to participate Not applicable.

\section{Publisher's Note}

Springer Nature remains neutral with regard to jurisdictional claims in published maps and institutional affiliations.
Received: 9 March 2020 Accepted: 9 May 2020

Published online: 25 May 2020

\section{References}

1. Mauri T, Turrini C, Eronia N, Grasselli G, Volta CA, Bellani G, Pesenti A (2017) Physiologic effects of high-flow nasal cannula in acute hypoxemic respiratory failure. Am J Respir Crit Care Med 195:1207-1215

2. Mauri T, Alban L, Turrini C, Cambiaghi B, Carlesso E, Taccone P, Bottino N, Lissoni A, Spadaro S, Volta CA, Gattinoni L, Pesenti A, Grasselli G (2017) Optimum support by high-flow nasal cannula in acute hypoxemic respiratory failure: effects of increasing flow rates. Intensive Care Med 43:1453-1463

3. Frat JP, Thille AW, Mercat A, Girault C, Ragot S, Perbet S, Prat G, Boulain T, Morawiec E, Cottereau A, Devaquet J, Nseir S, Razazi K, Mira JP, Argaud L, Chakarian JC, Ricard JD, Wittebole X, Chevalier S, Herbland A, Fartoukh M, Constantin JM, Tonnelier JM, Pierrot M, Mathonnet A, Beduneau G, Deletage-Metreau C, Richard JC, Brochard L, Robert R (2015) High-flow oxygen through nasal cannula in acute hypoxemic respiratory failure. $\mathrm{N}$ Engl J Med 372:2185-2196

4. Azoulay E, Lemiale V, Mokart D, Nseir S, Argaud L, Pene F, Kontar L, Bruneel F, Klouche K, Barbier F, Reignier J, Berrahil-Meksen L, Louis G, Constantin JM, Mayaux J, Wallet F, Kouatchet A, Peigne V, Theodose I, Perez P, Girault C, Jaber S, Oziel J, Nyunga M, Terzi N, Bouadma L, Lebert C, Lautrette A, Bige N, Raphalen JH, Papazian L, Darmon M, Chevret S, Demoule A (2018) Effect of high-flow nasal oxygen vs standard oxygen on 28-day mortality in immunocompromised patients with acute respiratory failure: the HIGH randomized clinical trial. JAMA 320:2099-2107

5. Rochwerg B, Granton D, Wang DX, Helviz Y, Einav S, Frat JP, MekontsoDessap A, Schreiber A, Azoulay E, Mercat A, Demoule A, Lemiale V, Pesenti A, Riviello ED, Mauri T, Mancebo J, Brochard L, Burns K (2019) High flow nasal cannula compared with conventional oxygen therapy for acute hypoxemic respiratory failure: a systematic review and meta-analysis. Intensive Care Med 45:563-572

6. Russotto V, Myatra SN, Laffey JG (2019) What's new in airway management of the critically ill. Intensive Care Med 45:1615-1618

7. Casey JD, Semler MW (2019) Ventilation before intubation: how to prevent hypoxaemia? Lancet Respir Med 7:284-285

8. Vourc'h M, Asfar P, Volteau C, Bachoumas K, Clavieras N, Egreteau PY, Asehnoune K, Mercat A, Reignier J, Jaber S, Prat G, Roquilly A, Brule N, Villers D, Bretonniere C, Guitton C (2015) High-flow nasal cannula oxygen during endotracheal intubation in hypoxemic patients: a randomized controlled clinical trial. Intensive Care Med 41:1538-1548

9. Guitton C, Ehrmann S, Volteau C, Colin G, Maamar A, Jean-Michel V, Mahe PJ, Landais M, Brule N, Bretonniere C, Zambon O, Vourc'h M (2019) Nasal high-flow preoxygenation for endotracheal intubation in the critically ill patient: a randomized clinical trial. Intensive Care Med 45:447-458

10. Chanques G, Jaber S (2019) Nasal high-flow preoxygenation for endotracheal intubation in the critically ill patient? Maybe. Intensive Care Med 45:532-534

11. Ricard JD, Gregoretti C (2019) Nasal high-flow preoxygenation for endotracheal intubation in the critically ill patient? Pro. Intensive Care Med 45:529-531

12. Hanouz JL, Gerard JL, Fischer MO (2019) Nasal high-flow preoxygenation for endotracheal intubation in the critically ill patient? Con. Intensive Care Med 45:526-528

13. Hanouz JL, Lhermitte D, Gerard JL, Fischer MO (2019) Comparison of pre-oxygenation using spontaneous breathing through face mask and high-flow nasal oxygen: a randomised controlled crossover study in healthy volunteers. Eur J Anaesthesiol 36:335-341

14. Jaber S, Monnin M, Girard M, Conseil M, Cisse M, Carr J, Mahul M, Delay JM, Belafia F, Chanques G, Molinari N, De Jong A (2016) Apnoeic oxygenation via high-flow nasal cannula oxygen combined with non-invasive ventilation preoxygenation for intubation in hypoxaemic patients in the intensive care unit: the single-centre, blinded, randomised controlled OPTINIV trial. Intensive Care Med 42:1877-1887

15. Frat JP, Ricard JD, Quenot JP, Pichon N, Demoule A, Forel JM, Mira JP, Coudroy R, Berquier G, Voisin B, Colin G, Pons B, Danin PE, Devaquet J, 
Prat G, Clere-Jehl R, Petitpas F, Vivier E, Razazi K, Nay MA, Souday V, Dellamonica J, Argaud L, Ehrmann S, Gibelin A, Girault C, Andreu P, Vignon P, Dangers L, Ragot S, Thille AW (2019) Non-invasive ventilation versus high-flow nasal cannula oxygen therapy with apnoeic oxygenation for preoxygenation before intubation of patients with acute hypoxaemic respiratory failure: a randomised, multicentre, open-label trial. Lancet Respir Med 7:303-312

16. Schetz M, De Jong A, Deane AM, Druml W, Hemelaar P, Pelosi P, Pickkers P, Reintam-Blaser A, Roberts J, Sakr Y, Jaber S (2019) Obesity in the critically ill: a narrative review. Intensive Care Med 45:757-769

17. Casey JD, Janz DR, Russell DW, Vonderhaar DJ, Joffe AM, Dischert KM, Brown RM, Zouk AN, Gulati S, Heideman BE, Lester MG, Toporek AH, Bentov I, SelfWH, Rice TW, Semler MW (2019) Bag-mask ventilation during tracheal intubation of critically III adults. N Engl J Med 380:811-821

18. Vaschetto R, Longhini F, Persona P, Ori C, Stefani G, Liu S, Y Y Y, Lu W, Yu T, Luo X, Tang R, Li M, Li J, Cammarota G, Bruni A, Garofalo E, Jin Z, Yan J, Zheng R, Yin J, Guido S, Della Corte F, Fontana T, Gregoretti C, Cortegiani A, Giarratano A, Montagnini C, Cavuto S, Qiu H, Navalesi P (2019) Early extubation followed by immediate noninvasive ventilation vs. standard extubation in hypoxemic patients: a randomized clinical trial. Intensive Care Med 45:62-71

19. Yeung J, Couper K, Ryan EG, Gates S, Hart N, Perkins GD (2018) Noninvasive ventilation as a strategy for weaning from invasive mechanical ventilation: a systematic review and Bayesian meta-analysis. Intensive Care Med 44:2192-2204

20. Thille AW, Muller G, Gacouin A, Coudroy R, Decavele M, Sonneville R, Beloncle F, Girault C, Dangers L, Lautrette A, Cabasson S, Rouze A, Vivier E, Le Meur A, Ricard JD, Razazi K, Barberet G, Lebert C, Ehrmann S, Sabatier C, Bourenne J, Pradel G, Bailly P, Terzi N, Dellamonica J, Lacave G, Danin PE, Nanadoumgar H, Gibelin A, Zanre L, Deye N, Demoule A, Maamar A, Nay MA, Robert R, Ragot S, Frat JP (2019) Effect of postextubation highflow nasal oxygen with noninvasive ventilation versus high-flow nasal oxygen alone on reintubation among patients at high risk of extubation failure: a randomized clinical trial. JAMA 322(15):1465-1475. https://doi. org/10.1001/jama.2019.14901 